\title{
Intramaze cues and "odor trails" fail to direct choice behavior on an elevated maze
}

\author{
DAVID S. OLTON and CHRISTINE COLLISON \\ The Johns Hopkins University, Baltimore, Maryland 21218
}

\begin{abstract}
The relative importance of intramaze cues and extramaze cues in directing choice behavior on a radial arm maze was examined using a discrimination procedure which selectively rewarded rats for following only one set of cues. Rats in the intramaze group obtained food from a food cup on the end of each arm. Rats in the extramaze group obtained food from a food cup on a small platform just beyond the end of each arm. All rats were first shaped to perform correctly with the maze in a constant position. Then the maze was rotated to a new position after every choice. For rats in the intramaze group, the food moved with the arms, making intramaze cues relevant. For rats in the extramaze group, the food remained on the platforms (in the same position in the room), making extramaze cues relevant. Rats in the extramaze group performed almost perfectly during maze rotation, demonstrating that intramaze cues were not necessary to support accurate choice behavior. Rats in the intramaze group never performed better than chance, demonstrating that intramaze cues (from the rats, the reinforcement, and the apparatus) were not adequate to control choice behavior. The results of the present experiment are compared to those of other experiments describing the influence of "odor trails" or other olfactory stimuli on choice behavior in mazes.
\end{abstract}

In most maze procedures, there are many relevant and redundant stimuli that can influence discrimination behavior. Of particular concern is the possibility that unintended stimuli from the animals themselves, or from the reinforcements, may be sufficient to support accurate choice behavior. Numerous experiments have examined the role of "odor trails" by rats as they traverse a maze, or the "odor of reward" or the "odor of frustrative nonreward" emitted by rats as they experience positive reinforcement or extinction, respectively (Amsel, Hug, \& Surridge, 1969; Collerain, 1975; Collerain \& Ludvigson, 1972, 1977; Douglas, 1966; Dua \& Dobson, 1974; Means, Hardy, Gabriel, \& Uphold, 1971; Mellgren, Fouts, \& Martin, 1973; Morrison \& Ludvigson, 1970; Pratt \& Ludvigson, 1970; Wasserman \& Jensen, 1969). Although none of these experiments has proved that the discriminative stimulus resulting from the experimental procedure is truly olfactory (i.e., carried by the first cranial nerve), nonetheless they have provided a consistent body of evidence demonstrating that choice behavior in mazes can be influenced by intramaze cues, particularly those left by the animals being tested.

Other experiments have demonstrated that rats are very good at learning olfactory discriminations and

This research was supported in part by Research Grant 1-RO1MH-24213 from the National Institute of Mental Health. Requests for reprints should be sent to: David S. Olton, Department of Psychology, The Johns Hopkins University, Baltimore, Maryland 21218. The authors thank J. Krach for preparation of the manuscript. can rapidly develop a learning set for olfactory stimuli (Slotnick \& Katz, 1974). In addition, the odor from a single Noyes food pellet in an arm of a $\mathrm{T}$ maze can be sufficient to direct rats to that arm (Southall \& Long, 1969). Taken together, the data raise the possibility that the choice behavior of rats in any type of maze procedure may be guided by cues from the rats themselves or from the reinforcements, rather than by the intended discriminative stimuli.

In a series of experiments with a radial arm maze, Olton and others have argued that intramaze cues have no effect on the choice behavior of rats (Maki, Brokovsky, \& Berg, 1979; Olton, 1978; Olton, Collison, \& Werz, 1977; Olton \& Samuelson, 1976; Zoladek \& Roberts, 1978). However, the only data supporting this hypothesis come from a preference test in which equivalent rewards were provided for choosing on the basis of either extramaze or intramaze cues. Such a procedure is only a weak test of the role of intramaze cues, because there is no differential reinforcement for ignoring extramaze cues. A stronger test is to use a discrimination procedure in which reward is provided if and only if the rats choose on the basis of intramaze cues. The present experiment used such a procedure to determine if rats could learn to follow intramaze cues in the radial arm maze.

\section{METHOD}

\footnotetext{
Subjects

Eight male albino rats, derived from a Sprague-Dawley strain and born in the Johns Hopkins colony, served as subjects. They
} 
were housed in group cages until they were about 100 days old, when they were moved to individual cages and food deprived to $85 \%$ of their free-feeding weights. Water was available in the cages at all times. Sufficient food to maintain the rats at the desired body weight was provided approximately $1 \mathrm{~h}$ after each day's testing.

\section{Apparatus}

The apparatus was a radial eight-arm maze, elevated $65 \mathrm{~cm}$ above the floor. Each of the arms was $87 \mathrm{~cm}$ long and $7 \mathrm{~cm}$ wide. The floor of each arm was wood. The sides, $10 \mathrm{~cm}$ high, and top were made of $1 / 2$-in. hardware cloth. Surrounding the center platform was a $30-\mathrm{cm}$-diam wall, $20 \mathrm{~cm}$ high. At the entrance to each arm, a hole, $8 \times 9 \mathrm{~cm}$, was cut into this wall. Each hole could be covered by a guillotine door, confining the rat to the center platform when desired. The doors were operated by strings led through a ceiling hook to a control panel on one wall. The maze was suspended from the ceiling so that it could be rotated.

In each arm, $5 \mathrm{~cm}$ from the far end, was a hole, $2 \mathrm{~cm}$ in diameter and $1 \mathrm{~cm}$ deep, which served as a food cup for rats in the intramaze group. About $1 \mathrm{~cm}$ beyond the end of each arm and separated from it, was a platform, $8 \mathrm{~cm}$ square, covered by hardware cloth except for the side facing the maze. In the center of this platform was a hole, $2 \mathrm{~cm}$ in diameter and $1 \mathrm{~cm}$ deep, which served as a food cup for rats in the extramaze group.

The maze was in an irregularly shaped room which was well illuminated and contained numerous extramaze cues. The experimenter sat to one side of the maze by the control panel for the guillotine doors.

\section{Procedure}

Rats were given one test series a day, 5 days a week. At the beginning of each test series, one 190-mg Noyes food pellet was placed in the food cup at the end of each arm (for the intramaze rats) or in the food cup on the platform at the end of each arm (for the extramaze rats). The rat was placed in the center compartment with the guillotine doors closed. All the doors were raised and the rat was allowed to go out an arm to obtain food. While the animal was on the arm, the guillotine doors to the other seven arms were closed; when the rat returned to the center platform, the guillotine door to the remaining arm was closed, confining him to the center for $15 \mathrm{sec}$. All the guillotine doors were raised again, and the same procedure was followed until all eight pieces of food had been obtained or until a total of $15 \mathrm{~min}$ had elapsed.

All rats were first trained with the maze in a fixed position until after they reached a criterion of at least seven correct responses in the first eight choices for 5 consecutive days. Then, after each choice, the maze was rotated $45^{\circ}(1 \mathrm{arm}), 90^{\circ}$ (2 arms), $135^{\circ}$ ( $3 \mathrm{arms})$, or $180^{\circ}$ ( $\left.4 \mathrm{arms}\right)$. The direction of rotation and the magnitude of rotation was varied haphazardly. When the maze was rotated, the food on the arms (intramaze rats) moved with it, while the food on the platforms (extramaze rats) stayed in the same location. Consequently, intramaze cues were relevant for the intramaze rats, while extramaze cues were relevant for the extramaze rats. The location of the food was the only difference in the procedure for these two groups.

\section{RESULTS}

All rats rapidly learned the control procedure with the maze in a fixed position and attained criterion performance within 15 test series. During the 5 tests of criterion, the mean number of correct responses in the first eight choices was $\mathbf{7 . 6}$ for the intramaze group and 7.7 for the extramaze group.

During the first few days of maze rotation, the performance of the rats in the extramaze group decreased slightly so that the mean number of correct responses during the first two blocks of 5 days was 7.2 and 7.4, respectively. By the end of testing, however, performance was consistently high and no rat had a mean score of less than 7.6 correct, responses in each of the last three blocks of 5 days. These data are summarized in Figure 1.

Rats in the intramaze group never performed well during maze rotation. The mean number of correct responses for the group never exceeded 5.4 in any block of 5 days. Over the 30-day period of maze rotation, the mean number of correct responses for the rats ranged from 5.0 to 5.2. No rat gave any evidence of performing better at the end of the 30 day period than at the beginning, and no rat performed better than expected by chance $(5.3$ correct responses in the first 8 choices-see Olton, 1978, for calculations).

\section{DISCUSSION}

The data from the extramaze group support those reported previously from the radial arm maze (Olton, 1978; Olton, Collison, \& Werz, 1977; Olton \& Samuelson, 1976), demonstrating that intramaze cues are not necessary for high choice accuracy. The data from the intramaze group are the first from a discrimination test procedure in the radial arm maze

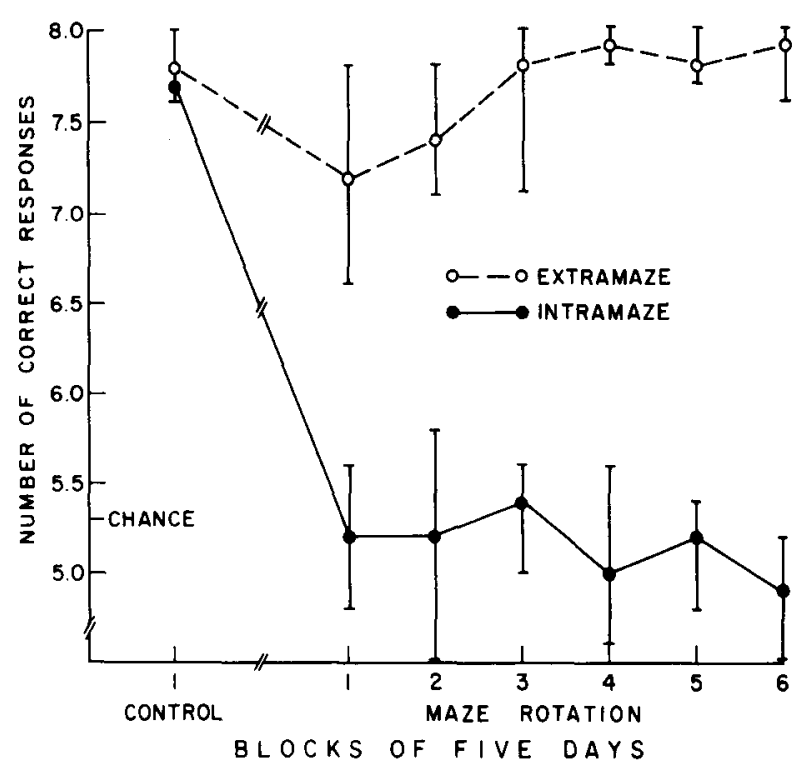

Figure 1. The number of correct responses in the first eight choices for blocks of five tests. The mean is represented by the dot, the range by vertical error bars. Performance of rats in the extramaze group is indicated by the open circles and dashed line, performance of rats in the intramaze group by the closed circles and solid line. Both groups performed well in the control condition. When the maze was rotated, the extramaze group continued to perform well while the intramaze group fell to chance levels and remained there for the duration of the experiment. 
and demonstrate that even when rats are selectively rewarded for following only intramaze cues, they are unable to do so. At least within the limits of the current testing procedure, intramaze cues from the rats, the reinforcements, and the apparatus are unable to support accurate choice behavior.

These data are important for two reasons. First, the intramaze discrimination procedure offers the greatest opportunity to find control of choice behavior by intramaze cues. The fact that no control was found supports the assumptions made in earlier work (see Olton, 1978) that accurate choice behavior in the radial arm maze is guided by the memory of spatial locations as defined by extramaze cues. Second, the results demonstrate that although the control of choice behavior by intramaze cues such as "odor trails" may be substantial in the appropriate circumstances, these circumstances are limited. More specifically, this "olfactory" control requires specific procedures to enhance the salience of the discriminative "odor" relative to other stimuli in the environment. This enhancement comes from increasing the intensity of the relevant "odor" (by summing over many different animals or from the same animal tested on many different trials, by providing an airflow carrying the odor to the animal, etc.), and by decreasing the intensity of any competing "odors" (by cleaning the maze between trials, using floors or walls with only a single type of "odor", etc.).

The present experiment does not indicate that rats can never learn to follow odor trails in a maze, and such a conclusion is obviously false (Vincent, 1915). The testing procedure used here strongly favors control by extramaze stimuli because extramaze stimuli are more salient than intramaze stimuli. If extramaze stimuli were suppressed and rats were rewarded for following only intramaze cues from the very first, then olfactory control might be enhanced (see Honzik, 1936). Such an experiment, of course, would be markedly different from the usual elevated maze procedure that was investigated here.

In summary, previous data suggest that intramaze cues and "odor trials" may have a strong influence on choice behavior in a maze, providing that specific steps are taken to enhance the salience of the relevant stimulus and suppress the salience of irrelevant stimuli. In the more usual maze task where neither of these steps are taken, intramaze cues appear to have little, if any, discriminative power.

\section{REFERENCES}

Amsel, A., Hug, J. J., \& Surridge, C. T. Subject-to-subject trial sequence, odor trails, and patterning at 24-h ITI. Psychonomic Science, 1969, 15, 119;120.

Collerain, I. Frustration odor of rats receiving small numbers of prior rewarded running trials. Journal of Experimental Psychology: Animal Behavior Processes, 1975, 4, 120-130.

Collerain, I. J., \& Ludvigson, H. W. Aversion of conspecific odor of frustrative nonreward in rats. Psychonomic Science, $1972,27,54-56$

Collerain, I. J., \& Ludvigson, H. W. Hurdle-jump responding in the rat as a function of conspecific odor of reward and nonreward. Animal Learning \& Behavior, 1977, 5, 177-183.

Douglas, R. J. Cues for spontaneous alternation. Journal of Comparative and Physiological Psychology, 1966, 62, 171-183.

DuA, J. K., \& Dobson, M. J. Role of olfactory cues in acquisition and extinction of avoidance. Journal of Experimental Psychology, 1974, 103, 461-465.

Honzik, C. H. The sensory basis of maze learning in rats. Comparative Psychology Monographs, 1936, 13, 1-113.

Maki, W. S., Brokofsky, S., \& Berg, S. Spatial memory in rats: Resistance to retroactive interference. Animal Learning \& Behavior, 1979, 7, 25-30.

Means, L. W., Hardy, W. T., Gabriel, M., \& Uphold, J. D. Utilization of odor trails by rats in maze learning. Journal of Comparative and Physiological Psychology, 1971, 76, 160-164.

Mellgren, R. L., Fouts, R. S., \& Martin, J. W. Approach and escape to conspecific odors of reward and nonreward in rats. Animal Learning \& Behavior, 1973, 1, 129-132.

Morrison, R. R., \& Ludvigson, H. W. Discrimination by rats of conspecific odors of reward and nonreward. Science, 1970 , 167, 904-905.

Olton, D. S. Characteristics of spatial memory. In S. H. Hulse, W. K. Honig, \& H. Fowler (Eds.), Cognitive aspects of animal behavior. Hillside, $\mathrm{Nj}$ : Erlbaum, 1978.

Olton, D. S., Collison, C., \& Werz, M. A. Spatial memory and radial arm maze performance in rats. Learning and Motivation, 1977, 8, 289-314.

Olton, D. S., \& Samuelson, R. J. Remembrance of places passed: Spatial memory in rats. Journal of Experimental Psychology: Animal Behavior Processes, 1976, 2, 97-116.

Pratt, L. K., \& Ludvigson, H. W. The role of odor in latent extinction. Psychonomic Science, 1970, 20, 189-190.

Slotnick, B. M., \& Katz, H. M. Olfactory learning-set formation in rats. Science, 1974, 185, 796-798.

Southall, P. F., \& Long, C. I. Odor cues in a maze discrimination. Psychonomic Science, 1969, 16, 126-127.

VincENT, S. B. The introduction of an olfactory control. Journal of Animal Behavior, 1915, 5, 140-157.

Wasserman, E. A., \& Jensen, D. D. Olfactory stimuli and the "pseudoextinction" effect. Science, 1969, 166, 1307-1309.

ZoladeK, L., \& Roberts, W. A. The sensory basis of spatial memory in the rat. Animal Learning \& Behavior, 1978, 6, $77-81$

(Received for publication August 31, 1978; revision accepted October 24, 1978.) 